\title{
Identificación de metabolitos bioactivos de Neem (Azadirachta indica Adr. Juss.)
}

\author{
Identification of bioactives metabolites of \\ Neem (Azadirachta indica Adr. Juss.)
}

\section{Carolina Vega-Jarquín}

Departamento de Producción Vegetal. Facultad de Agronomía. Universidad Nacional Agraria, km 12 1⁄2 carretera Norte, Managua. Nicaragua, carolina.vega@ci.una.edu.ni

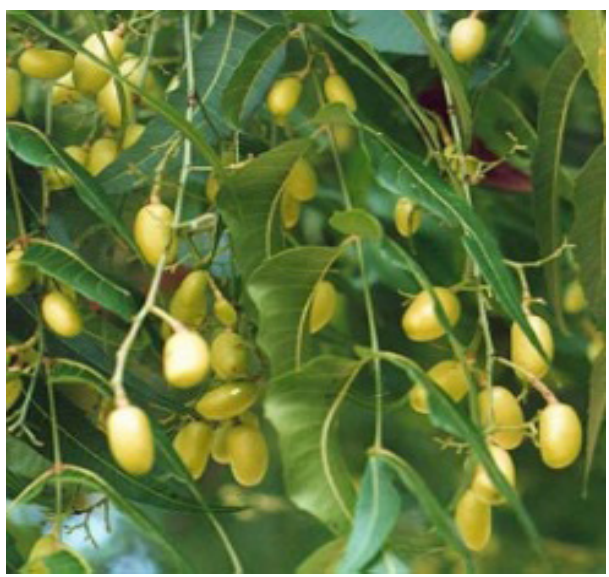

\section{RESUMEN}

Los productos del metabolismo secundario de plantas suelen ser de interés biotecnológico como plaguicidas naturales útiles para mejorar estrategias agroecológicas o en el manejo de ecosistemas más amigables con el ambiente. Con el propósito de iniciar estudios en esta temática se procedió a: a) establecimiento, en medios sólidos y en suspensión, de cultivos celulares de Azadirachta indi$c a$; b) extracción secuencial fraccionada, aislamiento y detección de Azadiractina mediante cromatografía de capa fina; c) identificación, cuantificación del compuesto por cromatografía de líquidos, y comprobación de su actividad biológica. Todas las actividades se realizaron en el laboratorio de biotecnología de células vegetales del centro de investigaciones y estudios avanzados (CINVESTAV), México, a finales del año 2009. Los resultados indican la presencia de terpenoides en los extractos obtenidos, la Azadiractina fue aislada y detectada mediante cromatografía de capa fina $\left(\mathrm{R}_{\mathrm{f}} 0,2\right)$. Este compuesto fue identificado también por la coincidencia de su tiempo de retención ( $20 \mathrm{~min}$ ) con el del estándar en la cromatografía líquida de alta resolución de la muestra semipurificada. Fue cuantificado interpolando su absorbancia en la curva de calibración obtenida con diferentes concentraciones del estándar. Se encontraron $1.67 \mathrm{mg} \mathrm{g}^{-1}$ peso seco de este compuesto en las semillas estudiadas, y mediante bioensayos fue comprobado el efecto fungicida del extracto. Adicionalmente, fueron establecidos cultivos in vitro.

Palabras clave: neem, limonoides, agroecosistemas, ecología química.

\section{ABSTRACT}

Secondary metabolites of plants are of biotechnological interest because, for example, they could be natural pesticides helpful to improve environmental friendly strategies or for agroecological management. In order to begin studies in this area it proceeded: a) establish cell suspension cultures of Azadirachta indica; b) extraction, isolation and detection of Azadirachtin by Thin Layer Chromatography; c) identification and quantification of AZA by Liquid Chromatography, and verification of their biological activity. All activities were conducted in the Laboratory of Plant Biotechnology of the Research Center and Advanced Studies (CINVESTAV), Mexico, at the end of 2009. Results indicate the presence of terpenoids in the extracts; Azadirachtin was isolated and detected by Thin Layer Chromatography $\left(R_{f} 0.2\right)$. This compound was also identified in semipurified sample by the coincidence of its retention time (20 min) with the chemical standard by Liquid Chromatography High Resolution; besides it was quantified by interpolation of their absorbance in the calibration curve obtained with different concentrations of the standard. In the analyzed seeds was found $1.67 \mathrm{mg} \mathrm{g}^{-1}$ dry weight of Azadirachtin and through bioassays was showed the fungicidal effect of the extract. Additionally, plant cell cultures in vitro were established.

Key words: Neem, limonoids, agroecosystem, chemical ecology. 
$\mathrm{E}$ n la actualidad existe una gran cantidad de problemas ambientales que presionan para que las actividades de desarrollo de la sociedad estén sustentadas en procesos y tecnologías limpias. Las políticas gubernamentales y planes de desarrollo agrícola que existen alrededor del mundo, orientan la reducción del uso de agroquímicos en general y promueven una producción agrícola sostenible, adicionalmente la tendencia agroecológica para el manejo de los agroecosistemas fomenta el uso de bioplaguicidas. Son muchos los productos que pueden ser obtenidos de las plantas y a lo largo de la historia de la humanidad, se han utilizado también principios activos o extractos procedentes de ellas como insecticidas, aunque entonces sin saber cuáles eran los compuestos que tenían esa propiedad.

Sin embargo, desde la mitad del siglo XX los plaguicidas químicos ocuparon un lugar preferencial y su uso continuo e indiscriminado ha tenido un impacto ambiental negativo que implica pérdidas de calidad de las aguas y el suelo, contaminación de hábitats, desarrollo de resistencias en las especies, riesgos para la salud humana y desequilibrios ecológicos.

La pérdida de las cosechas y de su calidad por la acción de plagas continua siendo uno de los principales problemas que enfrenta la agricultura y debido a los problemas ambientales generados por los plaguicidas químicos, los productos naturales con su diversidad estructural se han convertido en una alternativa para el diseño de métodos de manejo de plagas, efectivos y ecológicos (Opara y Obani, 2010).

Adicionalmente, es de interés estratégico fomentar el estudio y valoración de la biodiversidad local mediante el desarrollo de nuevos bioproductos que en combinación con el conocimiento tradicional conduzcan a un mayor aprovechamiento y conservación de la misma, contribuyendo así a convertir la ventaja comparativa de bio-riqueza en ventaja competitiva para promover el desarrollo sostenible.

El árbol de Neem (Azadiracta indica) es de crecimiento rápido, robusto, de hoja perenne, puede alcanzar una altura de $30 \mathrm{~m}$ y vivir por más de 200 años; es madera fina y dura, resistente al comején, de valor energético alto, pero no preciosa. La floración depende de las condiciones edafoclimáticas, en clima tropical ocurre entre los meses de abril y mayo pero suele prolongarse hasta diciembre intermitentemente y en menor porcentaje. La polinización es por Ceratopogónidos. Presenta inflorescencia en panícula con flores pequeñas, blancas, aromáticas. El árbol adulto produce entre 25 a 100 $\mathrm{kg}$ de frutos, drupas oblongas, amarillentas que contienen de una a dos semillas de color café (MARENA e INAFOR, 2002).

Posee una raíz pivotante de crecimiento rápido, clave para resistir la sequía y para sobrevivir en suelos pobres; este conjunto de características lo convierten en una opción alternativa para mejorar medios de vida del productor (Gruber, 1994).

Cuadro 1. Aspectos etnobotánicos de Azadirachta indica

\begin{tabular}{ll}
\hline \multicolumn{1}{c}{ Aspecto } & \multicolumn{1}{c}{ Detalles } \\
\hline Nombre científico & Azadirachta indica A. Juss \\
Nombre común & Neem, Margosa \\
Clase & Magnoliopsida \\
Familia & Meliaceae \\
Origen & Sur y sureste de Asia \\
Distribución & zonas tropicales y subtropicales de África, América y Australia \\
Lugar y fecha de recolección & km 13 Carretera Norte, Managua, 22 de octubre 2009 \\
Características del hábitat & $\begin{array}{l}\text { Sabana, destacándose el componente herbáceo y algunos pocos árboles predomi- } \\
\text { nantemente de } \text { A. indica }\end{array}$ \\
Usos & $\begin{array}{l}\text { Medicinales, abono verde, forraje, forestal, en Nicaragua se comercializa como } \\
\text { insecticida botánico (Neem 20) y para el manejo de plagas y control de parásitos } \\
\text { del ganado }\end{array}$ \\
\hline
\end{tabular}


El extracto de semillas del árbol de Neem provee de un insecticida natural para el manejo de plagas, ya que es conocido que afecta más de 300 especies de insectos, organismos patógenos y nematodos del suelo (Stoney, 1998). En estos árboles se encuentra la sustancia Azadiractina (AZA), triterpeno característico de la familia Meliaceae localizado en la corteza, hojas, frutos del árbol, y usualmente en mayor concentración en la semilla. Químicamente es muy interesante, debido a su compleja estructura que implica retos para su síntesis en laboratorio. Biológicamente es un compuesto importante por sus efectos negativos sobre el crecimiento y la capacidad de alimentarse de algunos insectos, artrópodos y de otros phyla relacionados (Coventry y Allan, 2001); pero sin efectos tóxicos significativos en vertebrados y el hombre (Adán et al., 1998).

Aunque la actividad biocida de extractos de Neem ha sido ampliamente reportada, el contenido de los componentes con esta actividad varía de acuerdo no sólo al estado de madurez del fruto, sino también posiblemente en relación a la variedad genética (Ramos et al., 2004). De manera que es pertinente señalar que la viabilidad económica y técnica de cualquier producto natural requiere no solo ser evaluado desde el punto de vista social, ambiental y financiero, sino que adicionalmente es un factor clave el poder disponer del producto en cantidades necesarias para satisfacer la demanda comercial del mismo.

Debe destacarse que en la agricultura moderna toda estrategia de manejo integrado que apoye alternativas no convencionales y más limpias requiere de fundamentos ecológicos, del conocimiento de las interacciones que ocurren desde el nivel químico, el biológico e incluso el social.

Con el interés de fortalecer estrategias biotecnológicas amigables con el ambiente que contribuyan al manejo ecológico de los sistemas de producción agrícola en Nicaragua, hemos procedido a extraer y determinar el contenido de AZA presente en semillas y hojas de $A$. indica así como a confirmar su actividad fungicida, lo que sentará bases para futuros estudios de optimización in vitro del proceso biológico de síntesis con fines de comercialización de este principio activo de bajo efecto residual.

\section{MATERIALES Y MÉTODOS}

Establecimiento de cultivos celulares como posibles productores de AZA. Frutos de $A$. indica fueron colectados en octubre del 2009 en árboles que crecen en campos alrededor de la Universidad Nacional Agraria, en Managua, Nicaragua. El establecimiento de cultivos celulares se realizó en el laboratorio de biotecnología de células vegetales del departamento de biotecnología del CINVESTAV, México D.F. Se diseñó un DCA con 12 tratamientos y dos repeticiones; los cultivos fueron colocados en medio Nm (Nitsch y Nitsch modificado) o Murashige y Skoog (MS) adicionado con 3\% de glucosa, y diferentes combinaciones y concentraciones de ácido naftalenacético (NAA) (1 o 1.86 mg/l); ácido indolbu- tírico (IBA) (1 mg/l); ácido 6 benzilaminopurina (BA) $(1 \mathrm{o}$ $0.56 \mathrm{mg} / \mathrm{l})$; ácido indolacético (AIA) $(1 \mathrm{mg} / \mathrm{l})$. En todos los casos el pH se ajustó a 6. Se agregó Phytagel ${ }^{\mathrm{TM}}(2 \mathrm{~g} / \mathrm{l})$ para solidificar el medio de cultivo. Los explantes fueron obtenidos de yemas axilares de plántulas procedentes de semillas de Nicaragua germinadas in vitro. El material vegetal fue previamente desinfectado con etanol $(70 \% \mathrm{v} / \mathrm{v}$ y Cloralex $15 \% \mathrm{v} / \mathrm{v})$. Los tratamientos fueron colocados en cuarto de crecimiento a $25 \pm 2{ }^{\circ} \mathrm{C}$ y 600 luxes. Se evaluó cualitativamente el desarrollo de callos, raíces, área foliar. Posteriormente, las mismas composiciones del medio nutritivo, pero sin Phytagel, fueron también utilizadas para los cultivos en suspensión los cuáles fueron establecidos a 100 rpm en similares condiciones de luz y temperatura.

Extracción, aislamiento, detección del triterpeno en cromatografía de capa fina. El tejido vegetal correspondiente a $0.5 \mathrm{~g}$ peso fresco (hojas o semillas) de $A$. indica se homogenizó en nitrógeno líquido, las grasas fueron removidas con hexano (1:10). Posteriormente, fueron adicionados $2 \mathrm{ml} \mathrm{de}$ éter de petróleo, las fracciones obtenidas fueron separadas, secadas con nitrógeno líquido y redisueltas en un $\mathrm{ml}$ de metanol. Una alícuota de estas fracciones fue aplicada a las placas con sílica gel para detectar el compuesto de interés al realizar la cromatografía de capa fina (TLC por sus siglas en inglés). La fase móvil usada fue hexano (3): etil acetato (7). La detección del compuesto de interés se realizó al observar el color de las manchas (rosado) después de asperjar la placa con vainillina ( $1 \%$ solución de $\mathrm{H}_{2} \mathrm{SO}_{4}$ ) y compararlas con el estándar. Como estándar se usó Azadiractina al 95 \% (Sigma) $\left(\mathrm{C}_{35} \mathrm{H}_{44} \mathrm{O}_{16}\right.$; peso molecular: 720.72).

Identificación, cuantificación de AZA y comprobación de su actividad biológica. Con el objetivo de semipurificar la muestra, la sílica correspondiente a las manchas que indicaban la presencia de Azadiractina fue separada de las placas y diluida en metanol. Después de dos días el extracto obtenido fue filtrado, colocado en rotavapor para remover el solvente y reconcentrado en metanol $(100 \mu \mathrm{l})$ : agua $(100 \mu \mathrm{l})$ para su posterior análisis por cromatografía líquida de alta resolución (HPLC).

UV espectrofotómetro

Diferentes concentraciones de estándar de Azadirachtin fueron preparadas con diferentes solventes y escaneadas en la región UV.

Finalmente, $100 \mu \mathrm{l}$ de la fracción extraída y semipurificada de la sílica fueron inyectados al equipo de cromatografía líquida de alta resolución (HPLC) para identificar el triterpeno. Las condiciones de corrida en HPLC para las soluciones metanólicas del extracto fueron columna $\mathrm{C} 18$, tasa de flujo $0.5 \mathrm{ml} \mathrm{min}^{-1}$, detector UV-VIS, longitud de onda $214 \mathrm{~nm}$, volumen de muestra $20 \mu \mathrm{l}$, fase móvil acetonitrilo-agua. La cantidad de AZA presente fue calculada interpolando su absorbancia en la curva de calibración obtenida con diferentes concentraciones del estándar. 
Actividad biológica. Durante el establecimiento de los cultivos in vitro se detectaron cepas de Fusarium spp creciendo en algunos de estos cultivos; por las características del crecimiento se postuló que el hongo podría estar conviviendo con los cultivos vegetales. Por sospechar un posible efecto elicitor fue entonces aislado, propagado e inoculado en condiciones asépticas a hojas de plantas de Neem. Para ello, hojas de plantas de $A$. indica creciendo previamente en macetas o potes, se desinfectaron en una solución de Cloralex $(15 \% \mathrm{v} / \mathrm{v})$ y posteriormente se lavaron con agua destilada, a continuación el limbo de la hoja fue introducido en tubo de ensayo con Fusarium en medio agar PDA (papa dextrosa). Finalmente, toda el área foliar de la planta se selló con bolsa plástica desinfectada para restringir el intercambio con el ambiente, el pote fue colocado en cámara de crecimiento a 24 $\pm 1{ }^{\circ} \mathrm{C}$ y luz continua.

Adicionalmente, se comprobó la actividad biológica del extracto mediante bioensayos. Para su preparación se usaron placas Petri con medio agar PDA (papa dextrosa) el que fue esterilizado, enfriado y mantenido a $12^{\circ} \mathrm{C}$.

Posteriormente, se difundieron en condiciones asépticas cinco $\mathrm{ml}$ de suspensión del inóculo obtenido de las cepas de Fusarium y se agregaron 5, 10 o $20 \mu \mathrm{l}$ del extracto metanólico utilizado en el HPLC. Las placas fueron dejadas en condiciones asépticas sin tapar, para permitir la evaporación del metanol. Después de una hora fueron selladas y mantenidas a una temperatura de $25^{\circ} \mathrm{C} \pm 2^{\circ} \mathrm{C}$ durante 10 días para su incubación. Se prepararon dos repeticiones y un control negativo de metanol al 50\%. Después de transcurrido el tiempo de incubación, se procedió a observar las zonas claras de inhibición del crecimiento para valorar la actividad antifúngica.

\section{RESULTADOS Y DISCUSIÓN}

Establecimiento de cultivos celulares. Estudiar la propagación in vitro de Neem no fue objetivo de este trabajo de investigación, no obstante, resulta de interés señalar algunos aspectos relacionados con este proceso puesto que los cultivos celulares son potenciales productores de Azadiractina. El desarrollo de callos, brotes foliares e incluso raíces (figura 1) ocurrió preferentemente en el medio MS. En el frasco último de la derecha se observa la formación de brotes foliares después de ocho semanas.

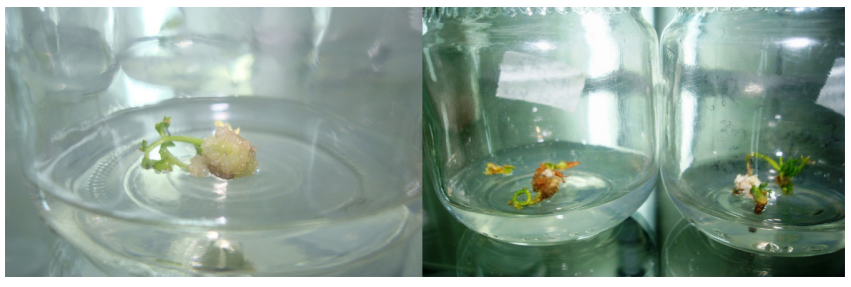

Figura 1. Formación de callos potencialmente embriogénicos de color crema, amarillo o café modulares y friables, obtenidos a partir de ápices de hojas de Neem cultivadas en medio MS suplementado con $1 \mathrm{mg} / \mathrm{l}$ de NAA y de BA respectivamente y 3\% de glucosa.
En el MS/2, con la concentración de sales inorgánicas reducida a la mitad, sin glucosa, ocurrió germinación de semillas de Neem. Fue observada una formación más acelerada de brotes foliares cuando callos provenientes de hojas se desarrollaron en condiciones de luz y en el medio adicionado con BA o con IBA. Tal como fue esperado, se formaron raíces en el medio MS adicionado con auxina, AIA ( $1 \mathrm{mg} / \mathrm{l}) \mathrm{y}$ con la concentración de sales reducida a la mitad.

En el MS adicionado con NAA (1.86 mg/l), BA (0.56 $\mathrm{mg} / \mathrm{l})$ y $3 \%$ de glucosa se logró el establecimiento de suspensiones celulares a partir de callos friables. Por otro lado, los problemas de oxidación en el medio MS fueron mínimos y la formación de callos semifriables o friables principalmente a partir de explantes de hoja se aceleró.

En la figura 2 se muestran raíces y suspensiones celulares establecidas en el medio MS pero generados a partir de explantes de hojas y callos respectivamente. Quraishi et al., (2004) señalan que las semillas almacenadas pierden su viabilidad, lo que podría conducir a dificultades en la conservación de Neem, especie con amplio uso en la industria maderera, medicinal y de agroquímicos. Incluso en algunos países, la demanda de uso a que ocasionalmente estas plantas son sometidas, podría conducir a su desaparición en los ecosistemas. Ante esta situación la regeneración in vitro de plántulas de Neem y los cultivos celulares, se constituye en una importante alternativa de propagación, conservación y para el mejoramiento y producción de concentraciones más altas de AZA o algún otro metabolito de interés.

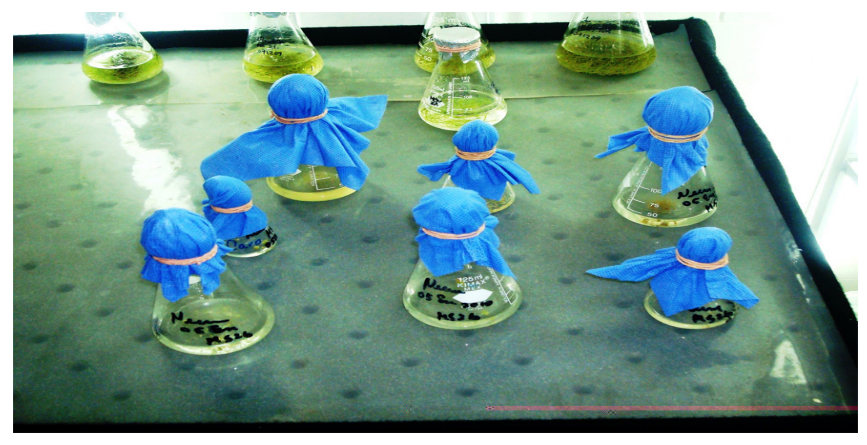

Figura 2. Cultivo in vitro de raíces (al fondo) y suspensiones celulares de $A$. indica en medio MS adicionado con NAA (1.86 mg/l), BA (0.56 $\mathrm{mg} / \mathrm{l})$ y $3 \%$ de glucosa.

Extracción, aislamiento, detección y cuantificación del triterpeno. Las placas de cromatografía asperjadas con vainillina $(1 \% \mathrm{v} / \mathrm{v})$ mostraron manchas que coincidieron con el estándar de referencia. El valor del $\mathrm{R}_{\mathrm{f}}(0.2)$ de la Azadiractina aislada desde las muestras coincidió con el del estándar (figura 3). En carriles 1 y 4 de izquierda a derecha se colocó la fase metanólica del extracto obtenido a partir de hojas, en carril 2 está la fase hexánica; 3 y 5 fase metanólica y hexánica respectivamente de muestras obtenidas a partir de semillas. En el carril S se colocó el estándar. La placa a la izquierda fue 
revelada usando vainillina-ac sulfúrico, por lo que se observa en el estándar y en algunas muestras el color rosado característico de AZA.

Este metabolito secundario vegetal fue detectado en todas las muestras o fases de la extracción. La placa a la derecha es la misma antes del revelado y bajo luz UV-corta, se observa en las muestras la presencia de otros terpenos posiblemente nimbina, salannina entre otros compuestos.

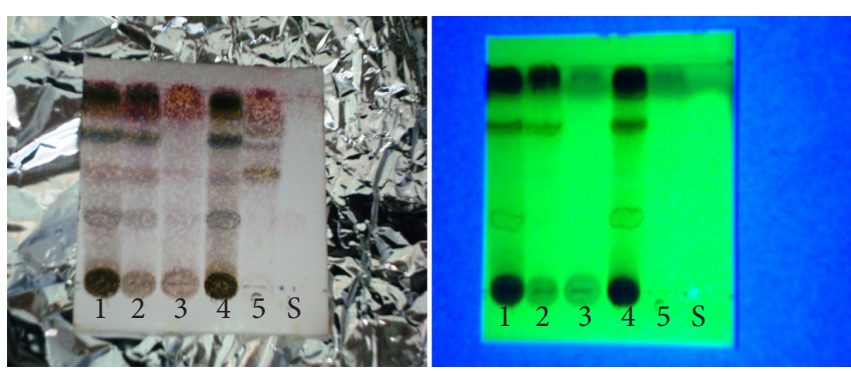

Figura 3. Cromatografía en capa fina que muestra la presencia de diversos compuestos y específicamente la Azadiractina, Rf (0.2), aislada a partir de hojas y semillas de $A$. indica; en todos los casos se colocaron $20 \mu 1$ de extracto crudo.

Cuando la Azadiractina aislada fue analizada utilizando HPLC, metodología analítica que permite la identificación del compuesto, el tiempo de retención del estándar, 20 minutos, coincidió con el de las muestras de semillas y hojas (figura $4 \mathrm{a}, \mathrm{b}, \mathrm{c})$. Como se observa en el recuadro a la derecha de la figura 4a, la longitud de onda donde el compuesto muestra su máxima absorbancia es $214 \mathrm{~nm}$. La cantidad encontrada en la semilla fue calculada en $1.67 \mathrm{mg} \mathrm{g}^{-1}$ de peso seco. Esparza-Díaz et al., (2010) reportan concentraciones de 2 478, 565, 422 y 150 ppm en el extracto metanólico, hexánico, oleoso y acuoso respectivamente, obtenido de semillas de Neem. Por otro lado, Arias et al., (2009) trabajando con una metodología especial que incluye técnicas de hidrodestilación y fluidos supercríticos para extraer aceites esenciales, encontraron aproximadamente $1.13 \mathrm{mg} \mathrm{g}^{-1}$ de AZA en semillas.

Aún se requiere mayor información acerca de la ruta metabólica de los limonoides, en particular de AZA, estudios en este sentido y relacionados con las variables de crecimiento del cultivo y con parámetros hidrodinámicos de transferencia de masa y calor serán necesarios para optimizar la producción en biorreactor de este insecticida natural.

Comprobación de actividad biológica y bioensayos. El crecimiento de Fusarium fue inhibido por una alícuota del extracto metanólico utilizado para la identificación del compuesto en HPLC, como se muestra en la placa del centro en la figura 5. El efecto fungicida de extractos de Neem ha sido previamente reportado (Bowers y Locke, 2000) y el bioensayo realizado durante este estudio confirmó la actividad antifúngica de los extractos, como se muestra en la placa del lado izquierdo de esta figura.

Se midió el crecimiento de la colonia después de cinco días, y se determinó $25 \%$ como el porcentaje de inhibición al tomar el control negativo como el $100 \%$. De acuerdo con Fernández y González (2008), hay actividad inhibitoria del crecimiento cuando ésta es mavor al $20 \%$.
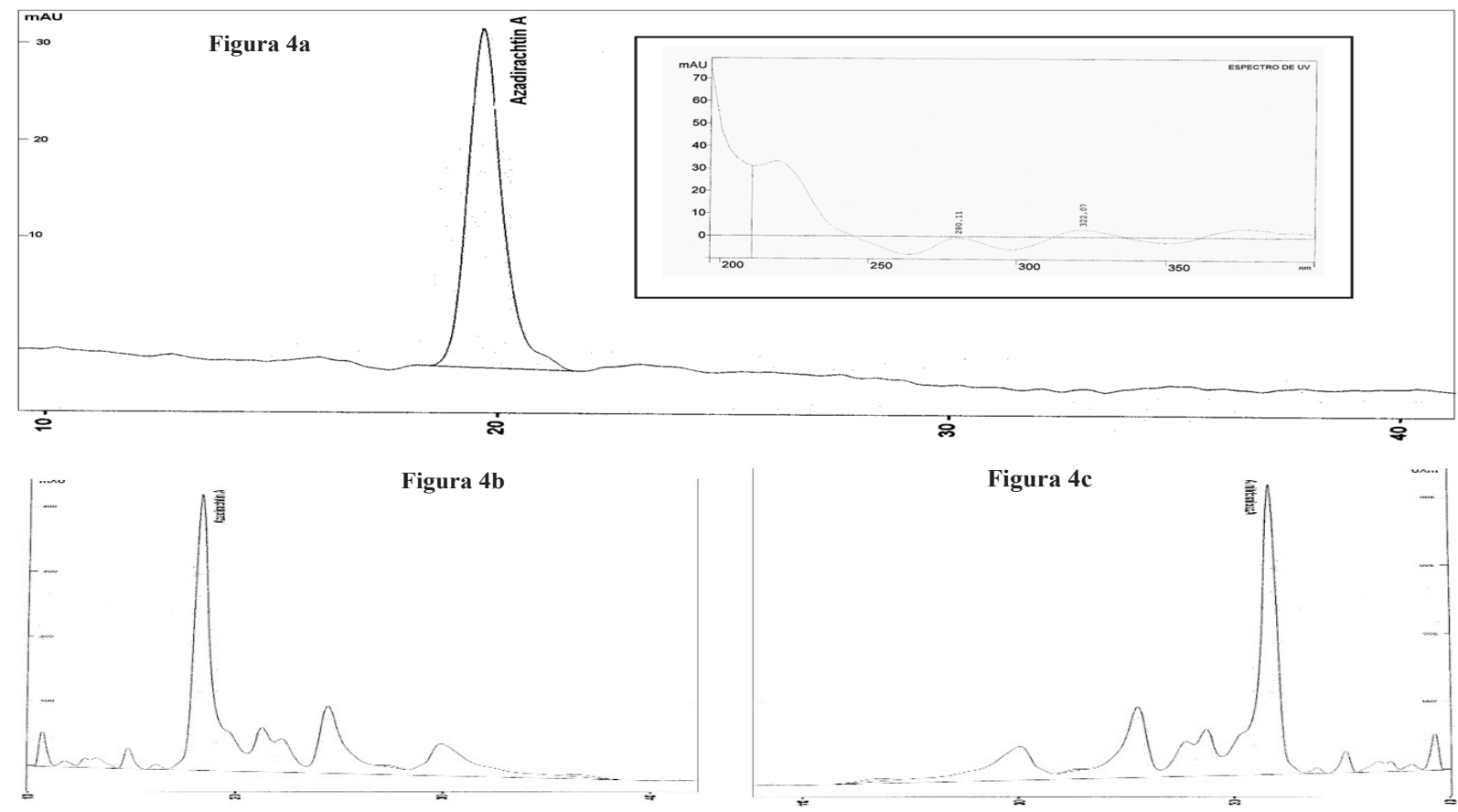

Figura 4. Cromatograma en HPLC del estándar de AZA (a); del extracto metanólico semipurificado de semillas (b); y de hojas (c) de $A$ indica. 


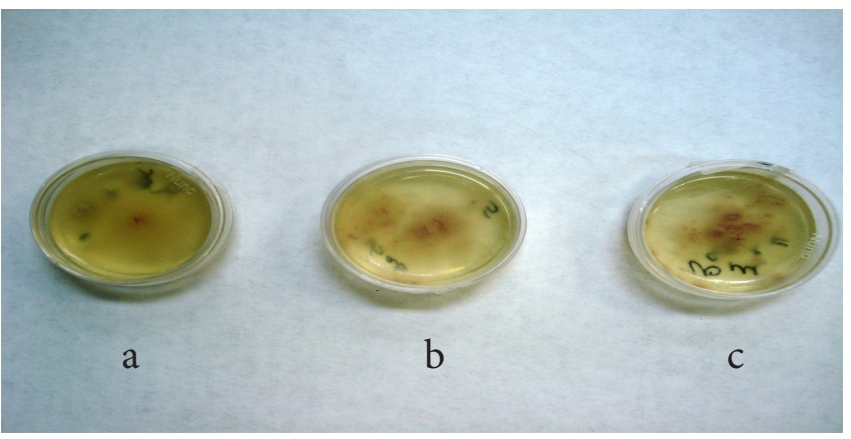

Figura 5. Fusarium spp creciendo con $10 \mu 1$ del extracto metanólico obtenido de semillas (a); con metanol al 50\%, control negativo (b); y en medio agar PDA (c).

Al menos 25 principios activos de Neem con actividad biológica sobre artrópodos han sido aislados (Isea et al., 2013). No obstante, si bien es importante obtener altas concentraciones de AZA en los extractos; no debe obviarse que también podrían estar presentes otros terpenos, visibles en las placas de TLC (figura 3) y en los cromatogramas (figura 4a y 4b), que posiblemente ejercen un efecto tóxico aditivo. Característica que agrega cualidades a este producto natural ya que obstaculiza el desarrollo de resistencias en los microorganismos patógenos.

Como se ha mencionado la cepa de Fusarium spp utilizada en este estudio fue aislada de los cultivos in vitro de Neem; Girish y Shankara (2008) reportan diferentes especies de Fusarium identificados como hongos endofíticos presentes en la corteza interna de esta especie. Es necesario profundizar los bioensayos e investigar si la producción de terpenoides está relacionada con estrategias de adaptación de A. indica.

En otras especies vegetales las aplicaciones de extractos de $A$. indica, realizados sobre la base de estudios toxicológicos, podría convertirse en una medida preventiva viable del manejo del ataque de hongos fitopatógenos; usualmente, el porcentaje de reducción de una concentración dada de microorganismos modelos resulta ser una manera eficaz de evaluar la actividad antimicrobiana de compuestos naturales.

Por lo tanto, otros bioensayos y con un mayor espectro de organismos blancos deberán ser realizados con AZA purificada ya que sólo de esta manera será posible atribuir la actividad biológica a una determinada estructura química. Estudios de dosis-respuesta son recomendables para determinar la mínima concentración necesaria para controlar plagas y minimizar los efectos que este compuesto purificado o en extractos de Neem pudiera tener sobre organismos benéficos, los seres humanos y el ambiente. Aunque no fue posible realizar pruebas de $I D_{50}$ los bioensayos realizados indican un efecto negativo del extracto sobre el crecimiento de Fusarium spp.

Por otro lado, las bases de la quimiotaxonomía son útiles para ampliar el espectro de plantas biocidas y fundamentar estudios ecotoxicológicos, ya que se ha señalado que la presencia de ciertos metabolitos secundarios está relaciona- do con el estado evolutivo de la familia botánica y con los mecanismos de protección de estas especies contra herbívoros, patógenos u otros agresores, lo que sugiere que pueden producir compuestos activos de manera diferenciada, lo cual suele correlacionarse con la posición sistemática de la especie (Gottlieb et al., 1995; Gottlieb y Borin, 2004).

En el contexto del manejo sostenible fundamentado en el conocimiento de las interacciones agroecológicas, este tipo de productos se constituyen en una alternativa viable para el productor, incluso con rasgos culturales que facilitan no solamente bajar costos de producción sino también fortalecer el desarrollo de agroecosistemas amigables con el ambiente.

En este estudio hojas de planta de Neem fueron inoculadas (figura 6), con la cepa de Fusarium que fue aislada de los cultivos in vitro, con la intención de conocer más acerca de la respuesta fisiológica de la planta al investigar efecto elicitor en la producción del compuesto de interés. En la figura $6 \mathrm{~b}$ puede observarse leve clorosis en dichas hojas después de dos días de inoculación del hongo. No obstante, los ensayos realizados hasta el momento no permiten postular si AZA es o no una fitoalexina, en este sentido es preciso realizar más estudios relacionados con su biosíntesis y las enzimas que la regulan.

También es necesario conocer más de la actividad biocida de estas biomoléculas, lo que requiere de la participación multidisciplinaria de especialistas para profundizar en el conocimiento del gran número de variables que pueden afectar la actividad y la calidad de los extractos, y además debe optimizarse el uso de estos productos naturales como parte de estrategias de manejo agroecológico de diversos cultivos.

Todo lo anterior ratifica la importancia agroecológica de estudios que permitan profundizar en el conocimiento científico de las propiedades químicas de las especies vegetales propias del país, zona o localidad.

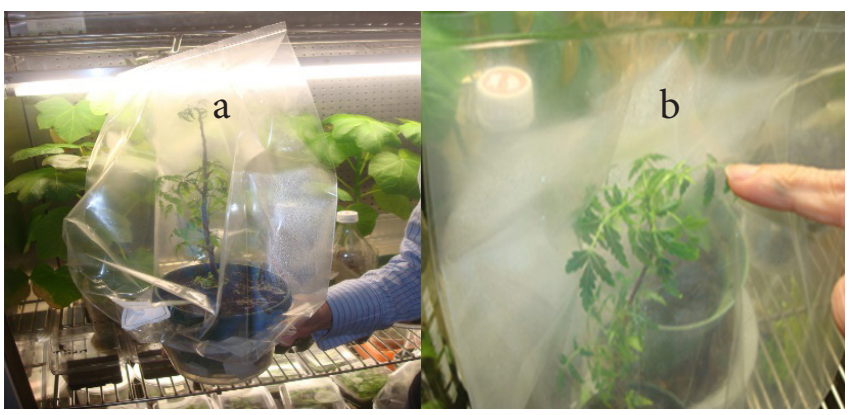

Figura 6. Plantas de Neem creciendo en condiciones asépticas (a), planta de Neem elicitada con Fusarium spp con clorosis en zona apical (b).

\section{CONCLUSIONES}

Utilizando el medio MS se lograron establecer cultivos celulares, incluso de cultivos de raíces y de células en suspensión de $A$. indica. El extracto metanólico obtenido procedente de la semilla y con un contenido de $1.67 \mathrm{mg} \mathrm{g}^{-1}$ de AZA mostró $25 \%$ de actividad antifúngica. Las propiedades biocidas del extracto dependen de la composición química conformada 
por diversos terpenos, entre los cuales la Azadiractina fue identificada utilizando cromatografía de capa fina y HPLC. Sin embargo, no existe suficiente información acerca del modelo de molécula a la cual atribuir la propiedad biocida, por lo que es necesario identificar el resto de compuestos y sus efectos así como la ruta de síntesis de estas biomoléculas. Asimismo se requiere conocer más acerca de los mecanismos fisiológicos de adaptación o de respuesta a estrés que $A$. indica posee para relacionar la estructura con la actividad biológica, ecológica, y toxicológica.

\section{AGRADECIMIENTOS}

Vega-Jarquín C. agradece al Consejo Superior Universitario Centroamericano (CSUCA)-Servicio Alemán de Intercambio Académico (DAAD) por el financiamiento para realizar esta corta estancia de investigación; a la Dra Ana Ramos-Valdivia por su apoyo y la oportunidad de trabajar en el laboratorio de cultivo de biotecnología de células vegetales del CINVESTAV, México, y a las autoridades de la Universidad Nacional Agraria por las facilidades brindadas.

\section{REFERENCIAS BIBLIOGRÁFICAS}

Adán, A; Soria, J; del Estal, P; Sánchez-Brunete, C; Viñuela, E. 1998. Acción diferencial de dos formulaciones de azadiractina sobre los estados de desarrollo de Ceratitis Capitata (Wiedemann) (Diptera: Tephritidae). Bol. San. Veg. Plagas 24:1009-1018.

Arias, D; Vázquez, G; Montañez, L; Álvarez, R; Pérez, V. 2009. Determinación del Azadiractina de los aceites esenciales del árbol de Neem (Azadirachta Indica). Revista Ingeniería UC 16:22-26.

Bowers, J; Locke, C. 2000. Effect of botanical extracts on the population density of Fusarium oxysporum in soil and control of fusarium wilt in the greenhouse. Plant Disease 84:300-305.

Coventry, E; Allan, J. 2001. Microbiological and chemical analysis of Neem (Azadirachata indica) extracts: new data on antimicrobial activity. Phytoparassitica 29:1-10.

Esparza-Díaz, G; López-Collado, J; Villanueva-Jiménez, J; Osorio-Acosta, F; Otero-Colina, G; Camacho-Díaz, E. 2010. Concentración de Azadiractina, efectividad insecticida y fitotoxicidad de cuatro extractos de Azadirachta indica A. Juss. Agrociencia 44:821-833.

Fernández, D; González, C. 2008. Evaluación in vitro de la actividad antifúngica del extracto foliar del árbol Azadirachta indica contra algunos hongos fitopatógenos. Trabajo de grado. Bogotá D.C. Colombia. Pontificia Universidad Javeriana

Girish, K; Shankara, B. 2008. Phomopsis azadirachtae - the die-back of neem pathogen. Electronic Journal of Biology 4:112-119.

Gottlieb, O; Borin, M. 2004. Quimiossistemática como ferramenta na busca de substâncias ativas. In: Simões, C.M.O. et al. Farmacognosia: da planta ao medicamento. 5 ed. Porto Alegre/Florianópolis: UFRGS/UFSC. p. 91-105.

Gottlieb, O; Borin, M; Brito, N. 1995. Chemosystematic clues for the choice of medicinal and food plants in Amazonia. Biotropica 27:401-6.

Gruber, K. 1994. Ficha ecológica del árbol Neem (Azadirachta indican A. Juss). Proyecto insecticida botánico Nim, Ed. CIEETS. Managua. NI.

Isea, G; Rodríguez, E; Hernández, A. 2013. Actividad garrapaticida de Azadirachta indica A. Juss (nim). Revista cubana de plantas medicinales 18:327-430.

MARENA (Ministerio del Ambiente y de los Recursos Naturales, NI); INAFOR (Instituto Nacional Forestal, NI). 2002. Guía de especies forestales de Nicaragua. Managua, NI. 304 p.

Opara, E; Obani, F. 2010. Performance of some plant extracts and pesticides in the control of bacterial spot diseases of Solanum. Agricultural Journal 5: 45-49.

Quraishi, A; Koche, V; Sharma, P; Mishr, S. 2004. In vitro clonal propagation of Neem (Azadirachta indica). Plant cell, tissue and organ culture 78:281-284.

Ramos, C; González, V; Soto, M; Engleman, E; Rodriguez, D. 2004. Variación en contenido de azadiractina en frutos de margosa durante su desarrollo. Revista fitotecnia mexicana 27:81-85

Stoney, C. 1998. Azadirachta indica: Nim, un árbol versátil para los trópicos del mundo. Hoja Informativa. Una guía para los árboles fijadores de nitrógeno del mundo. Fact 98-02S. Winrock International. Morrilton, AR. US. (en línea). Disponible en www. winrok.org/forestry/factnet.htm 